30 patients at risk of decompensation received IV/NG fluids 5 of which were within an hour.

Conclusions Patients at risk of decompensation due to an inborn error of intermediary metabolism are difficult to identify, and subsequently may not fulfil criteria for urgent assessment. Use of electronic alerts, in conjunction with training, departmental policies, and tailored management plans are likely to improve care, and have been implemented. Clarity of communication is key, specifically in identifying those most likely to deteriorate unexpectedly. However, this study was not designed to identify whether or how quickly any patient deteriorated. Further multicentre work is therefore crucial to delineate optimal assessment and intervention timelines, and will result in the development of national standards that will improve both short and long term outcomes for this vulnerable group.

\section{G84(P) CULTURAL RISK OF FOREIGN BODY ASPIRATION}

${ }^{1} \mathrm{O}$ Aziz, ${ }^{2} \mathrm{~K}$ Berry, ${ }^{1} \mathrm{~N}$ Makwana. ${ }^{1}$ Paediatrics, Sandwell and West Midlands NHS Trust, West Bromwich, UK; '2Emergency Department, Birmingham Children's Hospital, Birmingham, UK

\subsection{6/archdischild-2015-308599.83}

Introduction Wearing a head scarf is practised by certain cultures and religions including Muslim females. The head scarf may be fixed using pins, there have been previous case reports and case series of accidental inhalation of scarf pins from countries where wearing head scarves is common, such as Egypt, Kuwait and Turkey. We present a case series from a city in the UK, of females with accidental scarf pin inhalation.

Methods We searched for patients who had accidental scarf pin inhalation/indigestion presenting to a tertiary care Children's Hospital emergency department and also those that were referred to the Acute Paediatric Department at a District General Hospital from January 2008 to December 2014.

Results Over a 6 year period, a total of 12 patients presented with accidental scarf pin inhalation/ingestion. The age range of these patients ranged between 11 to 14 years, with a mean of 12.3 years. All were female Muslims, with no significant past medical history. The history given was that of the scarf pin was held in the mouth, and patients reported that they sneezed, were talking at the same time, laughing or were pushed by another person as a result of which they ingested or inhaled the pin. In 9 out of 12 of these patients, the x-ray's showed that the pin was in the stomach, and 6 of these patients had a repeat $\mathrm{x}$-ray to ensure that the pin had progressed within the GI tract. In two patients the pin was inhaled and was found to be in the left main bronchus and in one patient the pin was found to be in the upper airway on chest $\mathrm{x}$-ray. All three patients required laryngotracheobronchoscopy and foreign body removal.

Conclusion Health professionals working in a multi-cultural area need to be aware of this presentation and appropriate management. Wider educational measures are required in order to increase awareness regarding avoidance of placing the scarf pins in the mouth whilst placing head scarves.

\section{G85(P) FOLLOW UP OF ASYMPTOMATIC MICROSCOPIC HAEMATURIA/PROTEINURIA - DIFFERENT PERSPECTIVES OF PAEDIATRIC EMERGENCY MEDICINE, GENERAL PAEDIATRICS AND PAEDIATRIC NEPHROLOGY}

${ }^{1}$ RA Hastings, ${ }^{2}$ J Surridge, ${ }^{3}$ AJ Lunn. ${ }^{1}$ General Paediatrics, Nottingham Children's Hospital, Nottingham, UK; ${ }^{2}$ Children's Emergency Department, Derbyshire Children's Hospital, Derby, UK; ${ }^{3}$ Children's Renal and Urology Unit, Nottingham Children's Hospital, Nottingham, UK

\subsection{6/archdischild-2015-308599.84}

Aims To examine the practice of different sub-specialists with regard to the follow up of microscopic haematuria/proteinuria as an incidental finding in febrile children.

Methods Data from an online survey of responses to hypothetical scenarios of febrile children with incidental findings of microscopic haematuria/proteinuria in children with no overt signs of renal disease was collected. The survey was sent to registrars and consultants in paediatric emergency medicine, in paediatric nephrology and in general paediatrics. It asked for the doctors' current practice in arranging follow up of children with positive urine dipstick results.

Results A response to the survey was obtained from 34 paediatric emergency medicine (PEM) specialists, 10 paediatric nephrologists (PN) and 19 general paediatricians (PG). Table 1 shows the current practice of these doctors in managing children with $1+$ positive urine dipstick $(1+\mathrm{P} / \mathrm{H}$; either protein or blood $)$ and with $3+$ proteinuria and $3+$ haematuria $(3+\mathrm{P} \& \mathrm{H})$. Amongst consultants, PEM doctors were $3 \mathrm{x}$ more likely to investigate $3+$ haematuria and proteinuria as inpatients when compared with renal consultants. These differences suggest a trend towards increased follow-up recommended by paediatric nephrologists but with fewer admissions which was not statistically significant (Pearson Chi squared test).

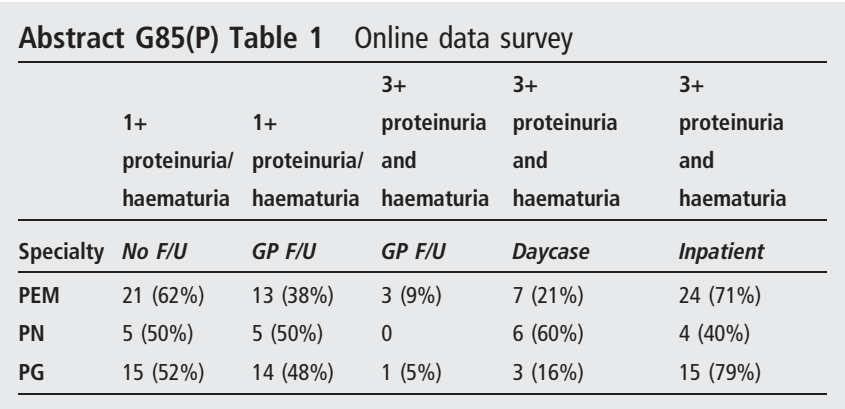

Conclusions An incidental finding of haematuria/proteinuria is common in CED. Approximately 2/3 of microscopic haematuria/ proteinuria in children without specific renal symptoms resolves. Ensuring resolution is important since up to $50 \%$ of children in whom it persists have renal disease. ${ }^{1}$ Here we show a trend for nephrologists to follow up more urine dipstick results but for PEM doctors to admit more children for inpatient investigations. PEM doctors and general paediatricians tend to have similar patterns of follow up.

\section{REFERENCE}

1 Geary DF, Schaefer F. Comprehensive Pediatric Nephrology. Philadelphia: Mosby, 2008 